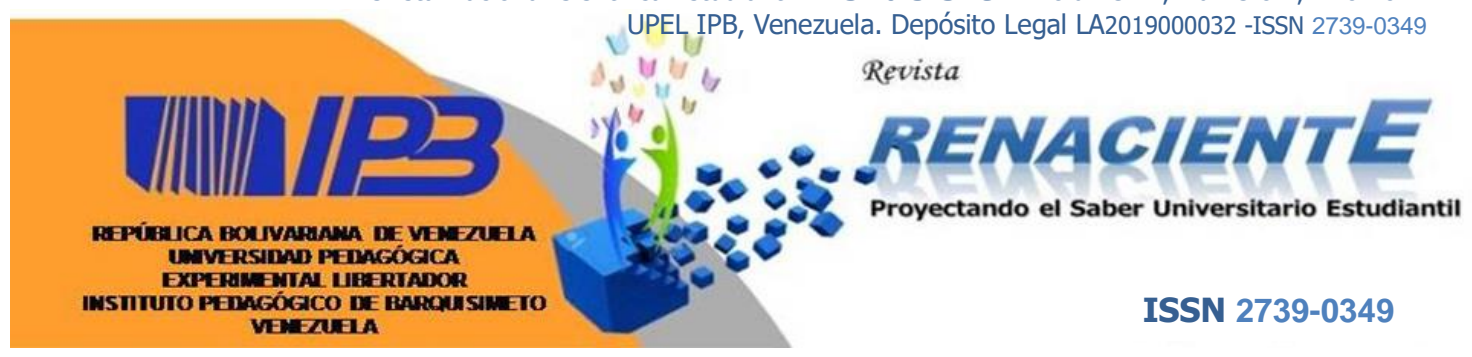

* Manuel F. Juliño Carliño
Julinoz83@gmail.com
https://orcid.org/0000-0002-1807-4142
* Franklin Ocaña Segura
Frank8p199@ gmail.com
https://orcid.org/0000-0002-3070-6966
* Jefferson E. Concha Iglesias
Jeffersonconchaiglesias8@gmail.com
https://orcid.org/0000-0001-8056-9499

Estudiantes del proyecto formativo "Vinculándome a la vida universitaria, carrera profesional de Ciencias Histórico Sociales y Geográficos Universidad Nacional Hermilio Valdizán de Huánuco, Perú.

Prof.: Edwin R. Esteban Rivera

Recibido: 29-08-2021

Revisado: 09-09-2021

Aceptado: 28-09-2021

\section{CONTAMINACIÓN AMBIENTAL Y SU INFLUENCIA EN LA SALUD}

\section{Resumen}

El presente artículo es una exploración a cerca de la contaminación ambiental y el efecto que pueda generar en la salud, tomando en consideración algunos aspectos como la contaminación del aire, del suelo, del agua y la contaminación acústica. Dicho apartado tiene como objetivo, dar a conocer y evidenciar el impacto que puede causar dicha amenaza. Para este estudio se ha elegido la investigación documental, mediante la referenciación y análisis de documentos escritos. Los resultados dan cuenta que la contaminación ambiental representa un asunto preocupante ante las consecuencias que está generando en la salud tanto fisicos como mentales. Urge que las personas e instituciones nacionales e internacionales puedan superar uno de los mayores desafíos, reducir la contaminación, para ello, los organismos deben establecer una serie de acciones que facilitan la evaluación de los riesgos que influyen en la salud.

Palabras Claves: contaminación ambiental, influencia, salud.

\section{ENVIRONMENTAL POLLUTION AND ITS INFLUENCE ON HEALTH}

\begin{abstract}
This article is an exploration of environmental pollution and the effect it can have on health, taking into consideration some aspects such as air, soil, water and noise pollution. The objective of this section is to make known and evidence the impact that this threat may cause. For this study, documentary research has been chosen, through the referencing and analysis of written documents. The results show that environmental pollution represents a worrying issue given the consequences that it is generating on both physical and mental health. It is urgent that national and international people and institutions can overcome one of the greatest challenges, reduce pollution, for this, agencies must establish a series of actions that facilitate the evaluation of risks that influence health.
\end{abstract}

Key Words: environmental pollution, influence, health. 


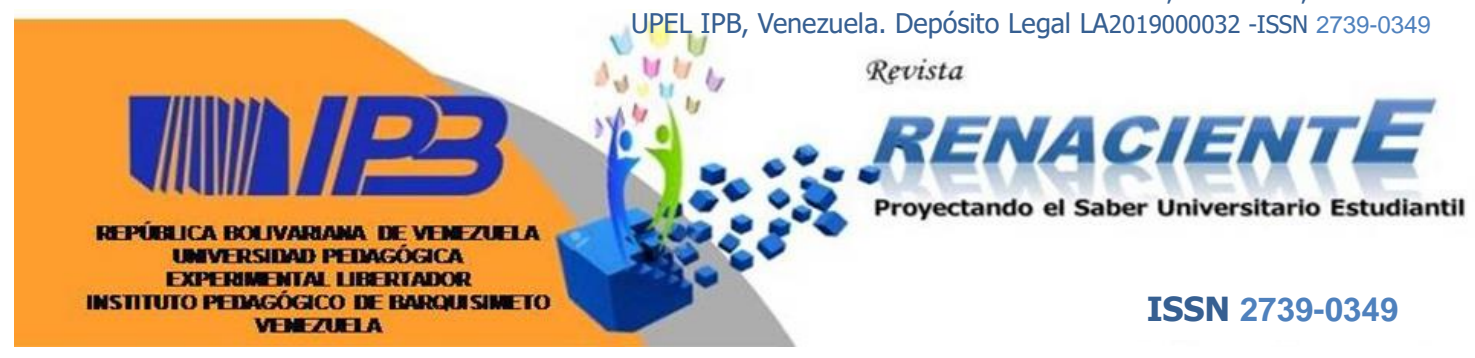

\section{Introducción}

La contaminación ambiental es la presencia de componentes nocivos, por lo tanto, produce daños en la salud de los seres vivos. "La contaminación ambiental es uno de los grandes problemas que enfrenta la humanidad actualmente, y se extienden con mucha mayor rapidez, por la cual el planeta está sufriendo un deterioro causado por diferentes motivos" (Seven, 2017 citado en Diestra, 2017, p. 93).

A tal efecto, debe precisarse que "La salud, según la Organización Mundial de la Salud (OMS), tiene una definición concreta: es el estado completo de bienestar físico y social que tiene una persona" (Estrada et al., 2016, p. 81). Es decir, la salud en términos generales hace alusión a la ausencia de enfermedades, tanto biológicas como psicológicas., ello en atención que según la OMS,

Cerca de siete millones de personas mueren cada año por la exposición a las partículas finas contenidas en el aire contaminado, las cuales penetran profundamente en los pulmones y el sistema cardiovascular y provocan enfermedades como accidentes cerebrovasculares, cardiopatías, cáncer de pulmón, neumopatía obstructiva crónica e infecciones respiratorias, por ejemplo, neumonía. (Osseiran \& Lindmeier, 2018).

De modo pues que la contaminación es la introducción de agentes biólogicos, químicos y físicos a un medio a la que no pertenece y que produce daños al ecosistema, estos daños pueden ser irreversibles. La contaminación ambiental afecta a la salud, a causa de la contaminacion cada año mueren millones de personas a nivel mundial, la gran cantidad de muertes son resultados, sobre todo, de enfermedades respiratorias y cardiovasculares que son causados por la polución del aire. Al abarcar la contaminación como tal, comprendemos como éste afecta al aire, agua, suelo, electromagnética y acustíca.

En consecuencia, se genera un desiquilibrio o alteracion en el estado natural del ambiente. Los efectos de la contaminación son muy peligrosos para todos los seres vivos de la planeta; ya que, pone en peligro a la salud del hombre; produce cambios climáticos, destruye la capa de ozono y destruye el ecosistema. 


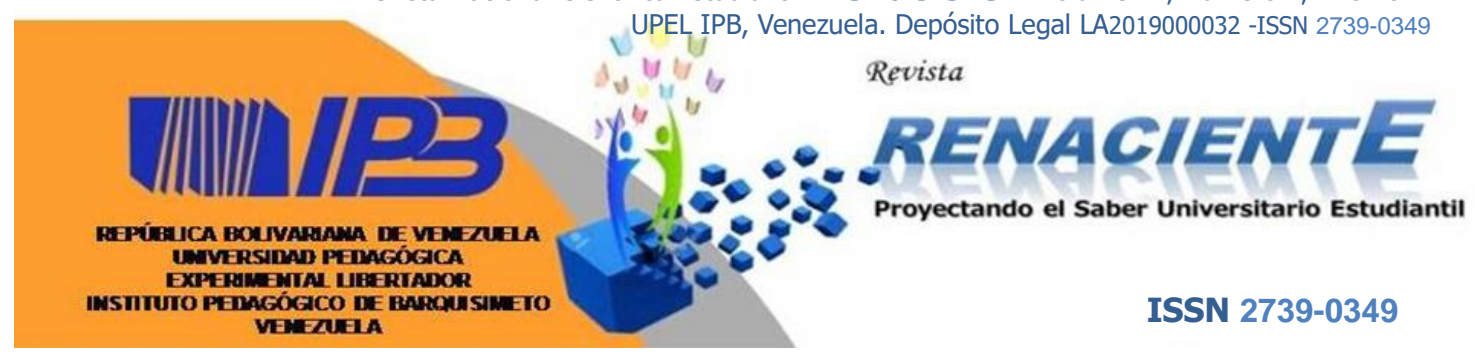

En la actualidad, podemos ver que los propios humanos somos los que causamos la contaminación, la quema de combustible, como el carbón petróleo, son los principales causas de este problema de contaminacion ambiental que pone el peligro no solo a nuestra naturaleza sino a nuestra propia salud (Ecologistas en Acción, 2006).

Muchas enfermedades han aumentado en los últimos años en el Perú, particularmente las enfermedades crónicas, las cuales estarían asociadas a contaminantes ambientales que se pueden encontrar en el aire y agua. Según Amabre et.al. (2017)“La contaminación de ríos y arroyos por agentes químicos se ha convertido en uno de los problemas ambientales más graves de nuestra sociedad. El ozono es un contaminante que produce afectaciones a la salud" (p. 1163). Es decir, la contaminación de los ríos y la explotación forestal, son las causas que generan las enfermedades respiratorias, afectando a gran cantidad de seres humanos.

El desarrollo económico y la globalización han generado diversas ventajas, pero al mismo tiempo han inducido la manifestación de nuevos riegos. Existen inconvenientes para reconocer la relación causal que existe entre medio ambiente y salud. La referencia disponible sobre las enfermedades relacionadas a la contaminación son resultados de experimentos en animales, estudios de laboratorio, estudios epidemiológicos y toxicológicos (Vargas, 2005).

Por lo expuesto, el presente trabajo de naturaleza documental, tiene como objetivo analizar la contaminación ambiental y su influencia en la salud.

\section{Desarrollo}

La contaminación ambiental es un fenómeno que afecta directa e indirectamente la salud de las personas, no solo se afecta la salud de la humanidad, pues tambien altera el equilibrio de los ecosistemas. En general, las personas y los animales de vida silvestre están expuestos a mezclas de más de dos sustancias tóxicas. Este contacto con contaminantes tóxicos puede darse durante procesos de producción, distribución o utilización de productos

77 Manuel Francisco Julio Carliño; Franklin Ocaña Segura y Jefferson Esidio Concha Iglesias.
Contaminación ambiental y su influencia en la salud 


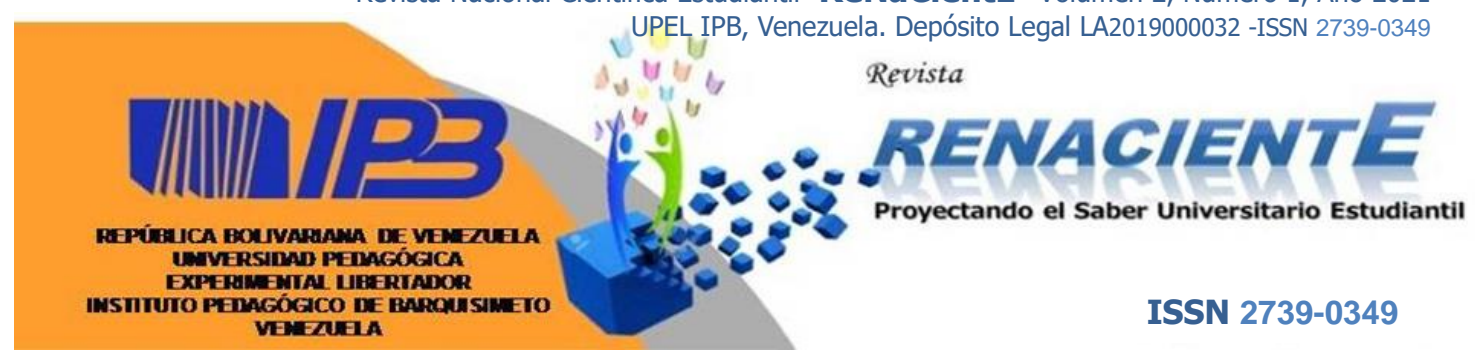

como medicamentos, alimentos, productos de limpieza, insecticidas, pesticidas, formulaciones industriales y artículos para el hogar, o bien cuando éstos son desechados al ambiente.

Actualmente se sabe que la mayoría de los seres vivos residen en áreas donde la contaminación ambiental es superior a los límites establecidos como saludables. Diferentes organizaciones dedicadas a la protección e investigación en materia de salud y del ambiente, como la Organización Mundial de la Salud, la Agencia Estadounidense de Protección del Ambiente y la Agencia Internacional para la Investigación del Cáncer han estimado que millones de personas y animales están expuestos a niveles elevados de compuestos tóxicos y que éstos pueden estar presentes en el ambiente de cielo abierto, en el agua, en el suelo, en el interior de las casas o en el lugar de trabajo de muchas personas (Ciencia, 2007).

\section{Formas de contaminación}

De acuerdo a su naturaleza la contaminación se da distintas formas:

\section{Contaminación del aire o atmosférica}

Es la alteracion de la calidad del aire en la atóosfera y la alteración del nivel común de los gases que existen en la atmósfera por ejemplo, el oxido nitroso, monóxido de carbono que se produce por el humo de las fábricas, gaces tóxicos, aerosoles, etc. Sus efectos inmediatos son el smog y el cambio climático. La contaminación del aire pueden provocar enfermedades como ataques (exacerbaciones) en personas con asma o enfermedad pulmonar. Estas enfermedades aumentan el riesgo de trastornos del corazón y de los vasos sanguíneos y pueden aumentar el riesgo de cáncer de pulmón (Lara, 2020).

\section{Contaminación del agua}

Es la lateración de las aguas continentales y los mares con sustancias tóxicas como aguas negras, petróleo, relaves, aguas térmicas, etc. Sus efectos más peligrosos es la 


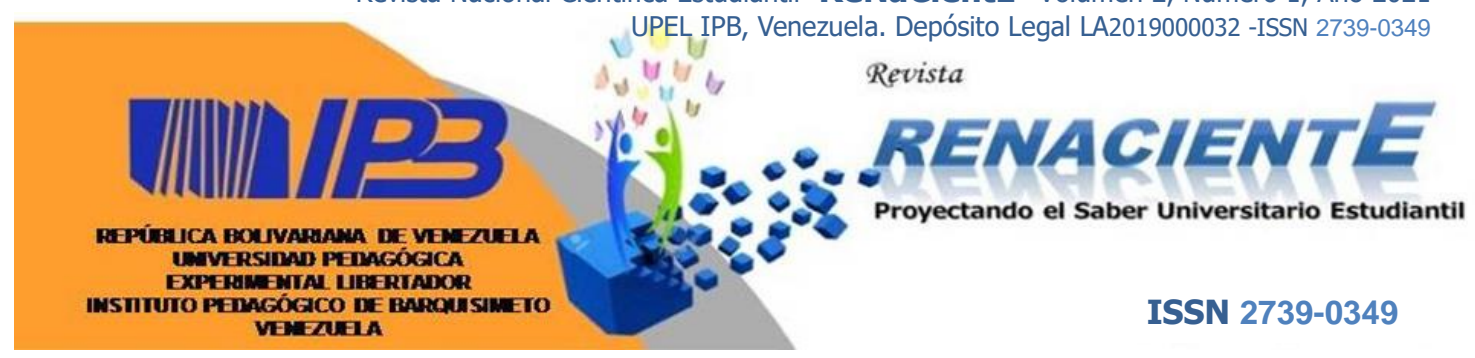

inutilidad del agua para los seres vivos y que en algunos casos requiere de procesos complicados para recuperar la pureza del agua.

El agua es un componente de suma necesidad para la vida, pero también puede ser un agente que daña la salud de las poblaciones, cuando está contaminada con agentes infecciosos o químicos. En el Perú el acceso al agua potable y saneamiento es muy bajo en el ámbito rural a diferencia del espacio urbano. La OMS define el agua contaminada como "aquella que sufre cambios en su composición hasta quedar inservible" (OMS, 2019). Es decir, es agua tóxica que no se puede beber ni se puede utilizar para realizar actividades esenciales como la agricultura, al consumir esta agua contamina podemos corer riesgo de enfermedades como la fiebre, cólera, disentería, etc.

La contaminación de agua se genera por diferentes tipos de vertidos: aguas de proceso, aguas fecales y aguas blancas. El primero es un vertido del proceso productivo, con lo que su carga contaminante va a depender de la actividad industrial. El segundo es generado en los aseos y asimilables a aguas residuales domésticas. Y el último, se les suele llamar "aguas crudas" por su carácter previo a la potabilización. Su importancia está en que son la base de la producción de agua para el consumo humano masivo (Vazquez, 2017).

\section{Contaminación del suelo}

El suelo es un recurso vital es el soporte físico donde habitan todo los seres vivos. Desde hace mucho tiempo la humanidad viene utilizando y desallorando actividades como la agricultura, ganadería, la infraestructura urbana, etc. Por tanto, la contaminación del suelo consiste en la introducción de elementos extraños al sistema suelo o la existencia de un nivel inusual de uno propio que, por sí mismo o por su efecto sobre los restantes componentes, genera un efecto nocivo para los organismos del suelo, sus consumidores, o es susceptible de transmitirse a otros sistemas (Martínez Sánchez et al., 2000 citado en Voltaire, 2000).

Es decir, la contaminacion del suelo son todo los elementos líquidos o sólidos que son muy dañinos para la salud del hombre. Los principales causantes de la contamianción 


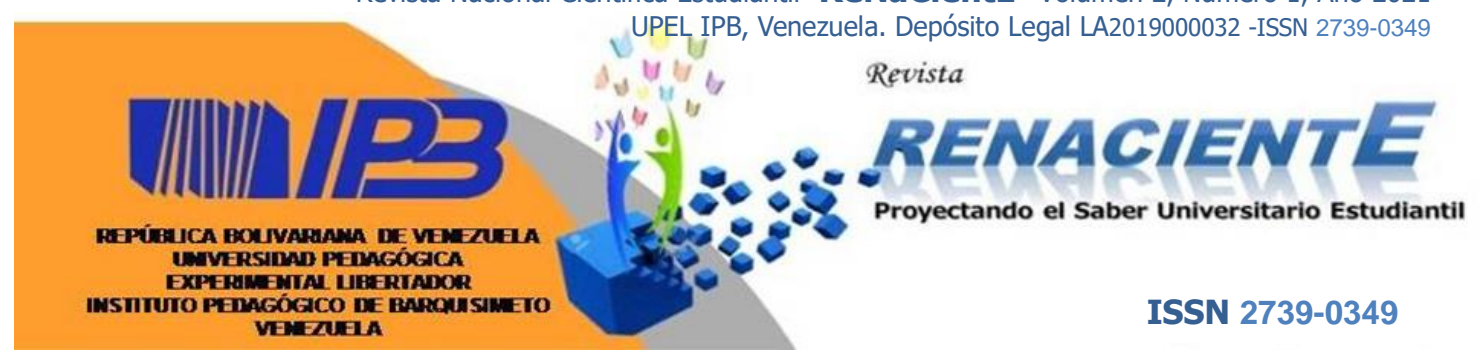

del suelo son: los plásticos, vídrios, latas, etc. En la actualidad en la agricultura utiliza ciertos productos que pueden ser causa de contaminación del suelo, entre ellos, abonos sintéticos, herbicidas e insecticidas, aunque son útiles para la agricultura, si se usan en exceso producen alteraciones en el suelo y reducen la producción.

Por otra parte, los plaguicidas de larga vida pueden concentrarse en las cadenas alimentarias y resultar tóxicos para el ser humano, matar especies útiles y alterar el equilibrio natural. Por ejemplo, sabemos que la salinización del suelo, debido al regadío intensivo de baja calidad, provoca la degradación del terreno y pérdidas de la capacidad de producción. Esto puede generar la pérdida de la fertilidad del terreno y de la biodiversidad.

\section{Contaminación acústica}

La presencia de ruido es un componente importante en la salud del hombre, el cual se debe tener muy en cuenta considerando los efectos que puede causar a la salud en distintas etapas de la vida. Se entiende como contaminación acústica al exceso de sonido que altera las condiciones normales del ambiente en una determinada zona. Por lo que se diferencia de otros contaminantes ambientales por ser el contaminante más barato de producir y necesita muy poca energía para ser emitido. Es complejo de medir y cuantificar. No deja residuos, no tiene un efecto acumulativo en el medio, pero puede tener efecto acumulativo en el hombre (Amable, et al., 2017).

El origen de los ruidos molestos en las ciudades provienen del transporte público, obras en construcción, reparaciones en la vía pública, centros comerciales y locales de esparcimiento. Desde el entorno institucional, se exige la ejecucipon de controles al transporte público, inspecciones a las obras en construcción, talleres, fábricas, locales de esparcimiento y actividades festivas. Se considera al ruido de tránsito, como el contaminante principal de las ciudades.

En este sentido, se debe exigir el cumplimiento de las reglamentaciones y los horarios adecuados para realizar actividades que generan ruidos, como reuniones y fiestas. Se hace

80 Manuel Francisco Julio Carliño; Franklin Ocaña Segura y Jefferson Esidio Concha Iglesias.
Contaminación ambiental y su influencia en la salud 


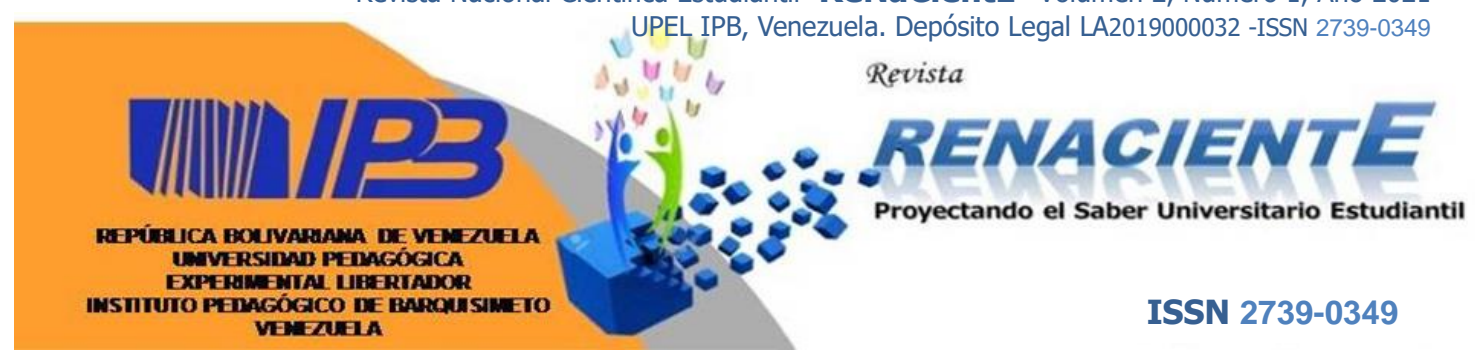

necesaria la elaboración de un programa de educación, comunicación y divulgación ambiental, con su correspondiente cronograma de ejecución, en materia de contaminación sonora. La atención a este tema debe fortalecerse en las comisiones provinciales y municipales de enfrentamiento a las indisciplinas sociales e ilegalidades. (Amable, et al., 2017).

\section{Tipos de contaminación}

\section{Contaminación no degradable}

Los contaminantes no degradables son que desconponen con el paso de muchos años por ejemplo el vidrio es un componente no biodegradable que tarda unos 4.000 mil años en descomponerce y tambien los plasticos tardan años para descomponer. La mejor forma de tratar los contaminantes no degradables es por una parte evitar que se arrojen al medio ambiente y por otra reciclarlos o volverlos a reutilizar. Una vez que se encuentran contaminando el agua, el aire o el suelo, tratarlos, o eliminarlos es muy costoso y, a veces, imposible. (Barahona, 2016)

\section{Contaminación de degradación lenta}

Son los contaminantes que demoran varias décadas o más tiempo para degradasrce. $\mathrm{Y}$ estos no descomponen de procesos naturales. Para tratar para tratar estos residuos contaminantes, lo mejor es lo mejor es resiclarlo o reutilizarlos y así evitar que acaben desechados al medio ambiente. la mayor parte del plástico son ejemplos. En el caso del plástico este tarda decenas de años en degradarse, aunque no lo hace totalmente ya que quedan los microplásticos siendo una gran amenaza para los seres vivos al introducirse en la cadena alimenticia. (Portillo, 2020)

\section{Contaminación degradable}

los contaminantes degradables o no persistentes se descomponen completamente o se reducen a niveles aceptables mediante procesos naturales físicos, químicos o biológicos.

81 Manuel Francisco Julio Carliño; Franklin Ocaña Segura y Jefferson Esidio Concha Iglesias.
Contaminación ambiental y su influencia en la salud 


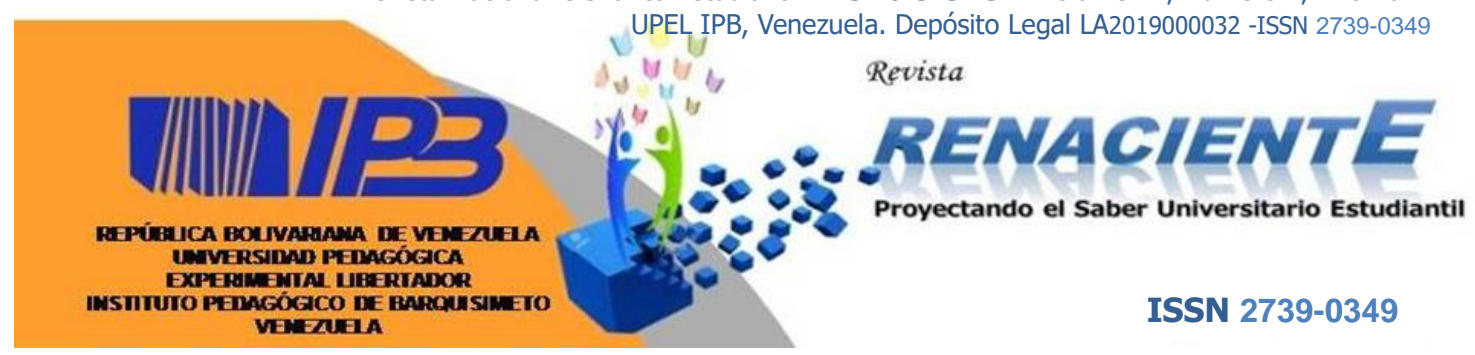

(Williams, 2013). En si lo que es producido por el planeta Tierra es degradable, pero tambien nos podemos hacercar a reutilizar las cosas y no botarlas o hacer un objeto mas a la gran contaminacion, porque de uno en uno se llega a miles. Tenemos como ejemplo las bolsas, son tan necesarias para el hombre; en ella cargamos y transportamos cosas.

\section{Contaminación biodegradable}

Son contaminantes que se degradan por procesos biológicos a niveles aseptables. los contaminantes químicos complejos que se descomponen (metabolizan) en compuestos químicos más sencillos por la acción de organismos vivos (generalmente bacterias especializadas) se denominan contaminantes biodegradables. Ejemplo de este tipo de contaminación son las aguas residuales humanas en un río, las que se degradan muy rápidamente por las bacterias, a no ser que los contaminantes se incorporen con mayor rapidez antes del proceso de descomposición. (Williams, 2013, p. 228)

\section{Contaminación atmosférica y su impacto en la salud}

Las consecuencias de la exposición a la contaminación atmosférica son múltiples y de diferente severidad, siendo los más afectados los sistemas respiratorio y cardiocirculatorio. Un estudio llevado a cabo en Francia, Suiza y Austria, indica que el 6\% de la mortalidad y un número muy importante de nuevos casos de enfermedades respiratorias en estos países puede ser atribuido a la contaminación atmosférica. La mitad de este impacto es debido a la contaminación emitida por los vehículos a motor. Junto a los anteriores efectos demostrados es importante considerar el impacto potencial de las exposiciones a la contaminación atmosférica durante la gestación y la primera infancia. Una reciente revisión sobre el tema muestra resultados que indican una asociación entre entre la exposición a la contaminación atmosférica con el bajo peso al nacer y el retraso en el crecimiento intrauterino, así como el efecto de las exposiciones tempranas sobre la salud infantil, incluyendo incremento de mortalidad (Ballester, 2005 pp. 159-175).

82 Manuel Francisco Julio Carliño; Franklin Ocaña Segura y Jefferson Esidio Concha Iglesias.
Contaminación ambiental y su influencia en la salud 
Factores modificadores del impacto de las variaciones del clima y la contaminación atmosférica

En diversos estudios realizados se ha registrado un mayor efecto de algunos de los contaminantes atmosféricos durante los periodos más cálidos. Así se ha descrito para la asociación del SO2 sobre la mortalidad y la morbilidad cardiovascular. En el estudio APHEA se encontró que tanto la temperatura media anual como la ubicación de la ciudad en Europa (Norte, Sur, Este), es decir, elementos vinculados con el estado climático, mantienen un rol modificador del efecto de la contaminación con la mortalidad.

El efecto de las partículas sobre la mortalidad fue mayor en las ciudades de clima más cálido. Se han sugerido diversas hipótesis para explicar estos hallazgos. Por un lado la medida de la contaminación atmosférica durante los meses cálidos podría ser un indicador más aproximado de la exposición total de la población, ya que la gente pasa más tiempo en la calle y las ventanas están más tiempo abiertas. Por otro lado, en los meses cálidos podría aumentar la susceptibilidad individual a la contaminación debido a procesos tales como el aumento del efecto de las partículas sobre el sistema de regulación de la viscosidad plasmática (Ballester, 2005 pp. 159-175).

Diversos estudios han mostrado un resultado mayor del ozono durante los días de temperatura más altas o en los meses más calurosos. En el estudio EMECAS se ha descrito un efecto del ozono sobre el número de ingresos por enfermedades circulatorias, que es estadísticamente significativo en los meses cálidos pero no en el resto del año.

\section{Contaminantes ambientales y sus efectos sobre la salud de la población}

\section{Contaminación acústica y su impacto en la salud}

La sonoridad intensa produce vibraciones dentro del oido pudiendo dañar las células ciliadas, a veces, las lesiones son pasajeras compensandose generalmente después de unos minutos o días, pero la exposición al ruido en un tiempo prolongado de 75 decibeles (db), 


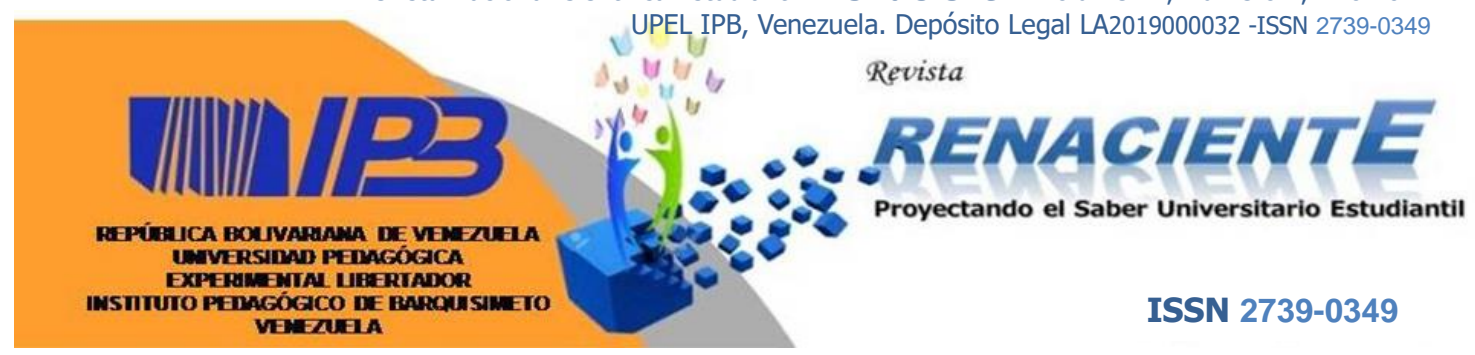

puede traer consigo la pérdida de la sensibilidad auditiva (Amable, et al., 2017). Dicho esto, la exposicón a la intensidad y a la prolongación del sonido excesivo aumenta el riesgo de pérdida del sentido de la audición.

La OMS, la CEE, CITMA, en estudios realizados sobre la contaminación sonora deducen que el ruido tiene efectos muy perjudiciales para la salud como trastornos de pérdida progresiva de audición, perturbación del sueño, irritabilidad, cansancio, estrés, genera agresividad, problemas estomacales. altibajos de la presión arterial, alteración de ritmo cardíaco, decaimiento del sistema inmunológico, disfunción de los niveles de segregación endocrina, vasoconstricción, problemas mentales, estados depresivos. Todas estas alteraciones provocan deficiencias en la vida cotidiana, tanto en el rendimiento laboral como en la relación con los demás (OMS, CEE y CITMA citado en Amable, et al., 2017).

\section{Contaminación del agua y su impacto en la salud}

Según la OMS (2019) "El agua contaminada y el saneamiento deficiente están relacionados con la transmisión de enfermedades como el cólera, otras diarreas, la disentería, la hepatitis A, la fiebre tifoidea y la poliomielitis" (p.19). Dicho esto las aguas residuales son la principal fuente de concentración de insectos y microorganismos contagiosos que se trasmiten a través del agua y el amiente provocando severos estragos en la salud, los insectos son portadores y trasmisores de diferentes enfermedades como el dengue.

Se calcula que unas 842000 personas mueren cada año de diarrea como consecuencia de la insalubridad del agua, de un saneamiento insuficiente o de una mala higiene de las manos. Sin embargo, la diarrea es ampliamente prevenible y la muerte de unos 361000 niños menores de cinco años se podría prevenir cada año si se abordaran estos factores de riesgo. (Organización Mundial de la Salud, 2019). Ahora bien, la afección más relacionada con la contaminación del agua es la diarrea, pues el consumo del agua infestada desencadena dicha enfermedad, hay también otras enfermedades como la esquitosomiasis, esta afección es 


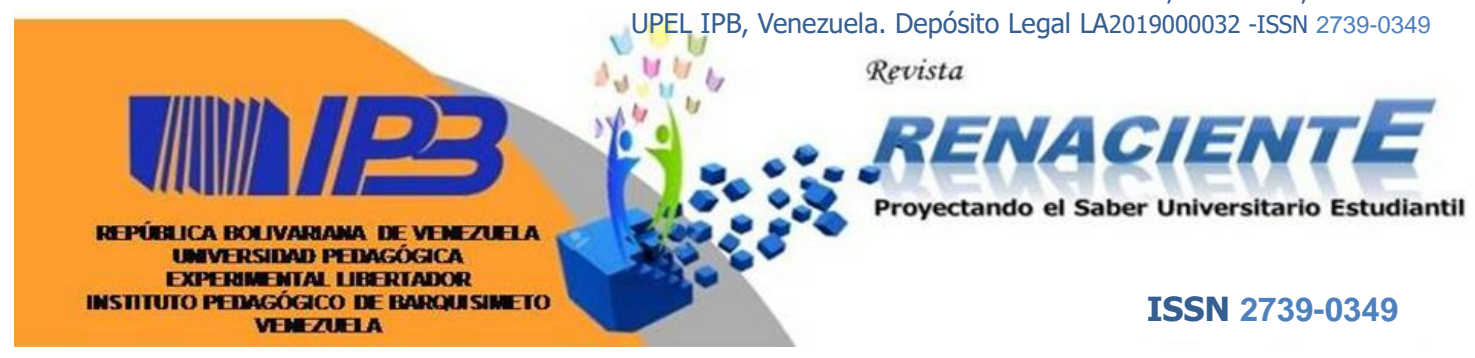

sumamente grave y crónica provacada por lombrises parasitarias engendradas por la exposición al agua residual.

\section{Contaminación del suelo y su impacto en la salud}

La contaminación del suelo trae consigo efectos catastróficos para todas las formas de vida en especial ala del ser huamano. Las prácticas agrícolas insostenibles reducen la materia orgánica del suelo generando la liberación de contaminantes en las aguas subterráneas que luego se acumulan en los tejidos de las plantas y pasan a los animales, a las aves y finalmente a los humanos (Organización de las Naciones Unidas para la Alimentación y la Agricultura, 2018)

Dicho contamiante puede causar diversas enfermedades y una excesiva mortalidad en la población, desde efectos agudos a corto plazo como intoxicaciones o diarrea, hasta otros crónicos a largo plazo, como el cáncer.

Una parte importante de los antibióticos utilizados ampliamente en la agricultura y en el ámbito de la salud humana se liberan en el medio ambiente tras ser expulsados del organismo al que se les administró. Estos antibióticos pueden filtrarse en los suelos y propagarse en el ambiente. Esto produce bacterias resistentes a los antimicrobianos, lo que disminuye la eficacia de los antibióticos. Cada año, unas 700000 muertes son atribuibles a bacterias resistentes a los antimicrobianos (Organización de las Naciones Unidas para la Alimentación y la Agricultura, 2018). Si no se detiene el problema, la resistencia a los antimicrobianos matará a más personas que el cáncer y tendrá un coste global mayor que el actual volumen de la economía mundial.

\section{Contaminación ambiental y su impacto en la salud de los peruanos}

La contaminación en el Perú hoy es un problema grave de la sociedad ya que está acabando poco a poco con la biodiversidad que tenemos, y en consecuencia trae graves problemas de salud, sociales y económicos. La contaminación más antigua y más persistente 


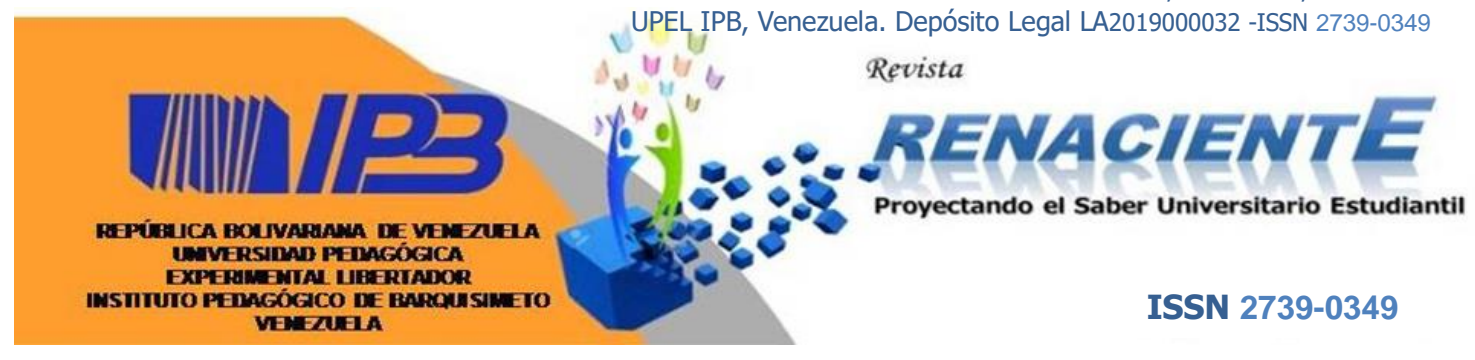

es generada por la actividad minera que, desde la llegada de los españoles, los ríos, los suelos y el aire se fueron envenenando producto de esta actividad económica, haciendo que hoy se pongan por delante intereses económicos de pocas personas en contra de la salud de ciudades enteras. Muchas enfermedades han aumentado de manera importante en las últimas décadas en los países en vías de desarrollo, particularmente las enfermedades crónicas, las cuales estarían asociadas a contaminantes ambientales que pueden estar en el agua y en el aire.

En el Perú el acceso al agua potable y saneamiento es aún muy bajo en el ámbito rural a diferencia de las zonas urbanas. La falta de acceso al agua segura y con un saneamiento básico inadecuado es causal de la prevalencia y persistencia de enfermedades diarreicas agudas (EDA) y las parasitosis. La mayoría de los efectos dañinos crónicos de la contaminación del aire ambiental se miden, en la actualidad, a través del material particulado menor a 2,5 micrones (PM 2,5), que penetran los espacios profundos del pulmón. El nivel promedio de Lima del 2001-2011, corresponde un riesgo relativo de aproximadamente 1,25 tanto para el cáncer pulmonar como para las enfermedades cardiovasculares/cerebrovasculares o cardiopulmonares (Gonzales, et al., 2014).

Según lo reportado por el Ministerio de Salud, anualmente se suceden 940 muertes de personas mayores de 20 años por cáncer pulmonar; 9550 muertes por enfermedades cardiovasculares; 1170 muertes por enfermedades cerebrovasculares en el Departamento de Lima en 2012, a esta cifra se debería agregar las muertes atribuibles a PM 2,5 ambiental en otras ciudades de Perú.

Los lugares más contaminados del Perú son la Oroya, Cerro de Pasco y Lima, según la organización, en dichas zonas permanece el eminente riesgo de exposición que provoca intoxicaciones crónicas en seres humanos, dichas afecciones son generadas principalmente por metales como el plomo, arsénico, mercurio y cadmio, que son captados por la población a través del aire o consumo de agua. (Carrillo, 2017). 


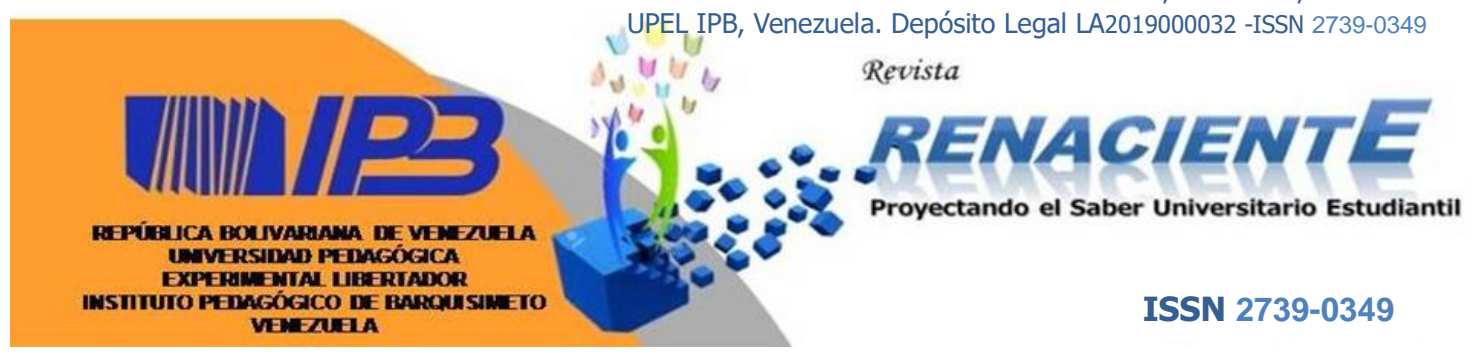

UPEL IPB, Venezuela. Depósito Legal LA2019000032 -ISSN 2739-0349

\section{Reflexiones finales}

La contaminación ambiental tiene un rol preponderante sobre el ser humano, el cual genera un impacto relevante y alarmante en la salud pública, dicha problemática abarca ciertos aspectos importantes como la contaminación del aire o atmosférica, la contaminación del agua, del suelo, la contaminación acústica los caules generan diversas enfermedades ya sean fisicas o psicológicas como el bajo peso al nacer y el retraso en el crecimiento intrauterino, pérdida de la audición, perturbación del sueño, irritabilidad, cansancio, estrés, agresividad, problemas estomacales, altibajos de la presión arterial, alteración de ritmo cardíaco, decaimiento del sistema inmunológico, disfunción de los niveles de segregación endocrina, vasoconstricción, problemas mentales, cáncer, estados depresivos, demostrando que a pesar de que el sistema de adaptación humana a los cambios negativos en este caso la asimilación de los efectos contaminates está preparado, el exceso de estos contaminantes en el medio ambiente, pueden provocar efectos irreversibles y serios a la salud (Lara, 2020; Ballester, 2005; OMS, 2019; Organización de las Naciones Unidas para la Alimentación y la Agricultura, 2018; Amable, et al., 2017).

Frente al escenario alarmante, se ha fijado un Sistema de Información sobre Salud Ambiental en el que están colaborando la Agencia Europea para el Medio Ambiente, numerosos países europeos, entre ellos España y la OMS. La aplicación de dicho sistema de indicadores armonizado facilita la toma de decisiones, la determinación de prioridades, la evaluación y gestión de los riesgos ambientales que influyen en la salud. En este sentido, a través de las Unidades de Sanidad Ambiental se ha precisado la creación y desarrollo de un sistema de vigilancia, inspección, control, el sistema de intercambio rápido de información sobre agentes y elemento contaminantes (Vargas Marcos, 2005).

Además, en Perú, existe una iniciativa para desarrollar sistemas de información ambiental que ampliará la red de monitoreo de la calidad del aire del país a otras seis ciudades como Trujillo, Chiclayo, Iquitos, Huancayo, Cusco y Piura (Banco Mundial, 2018). Manifestando que la población no está plenamente informada acerca de la importancia del

87 Manuel Francisco Julio Carliño; Franklin Ocaña Segura y Jefferson Esidio Concha Iglesias.
Contaminación ambiental y su influencia en la salud 


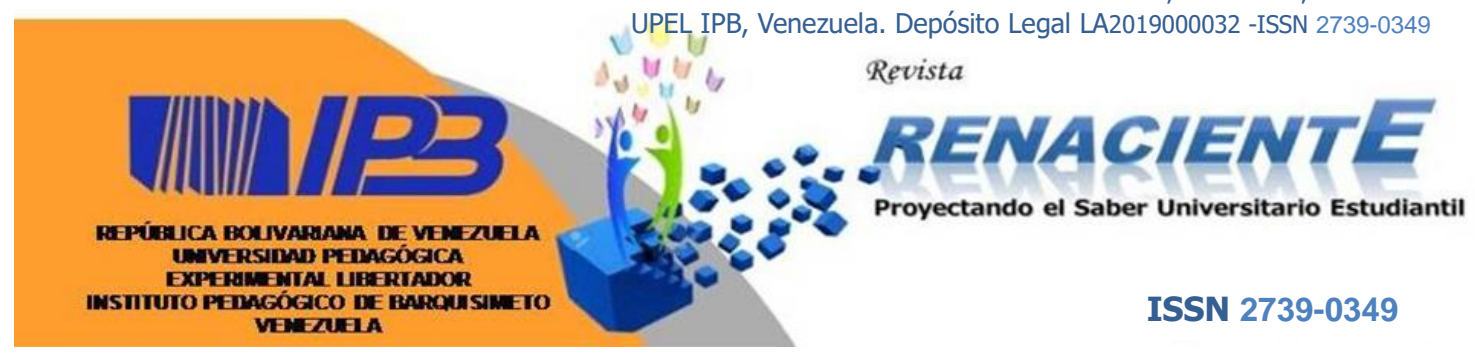

manejo ambiental, por lo que la alternativa de implementar las campañas de concientización y de incentivar a la investigación son necesarias para reforzar este tema que concierne a todos los habitantes.

\section{Referencias}

Amable Álvarez, I., Méndez Martínez, J., \& Bello Rodríguez, B. M. (2017). Influencia de los contaminantes atmosféricos sobre la. Revista Médica Electrónica, 39(5), 11601170. Obtenido de http://scielo.sld.cu/pdf/rme/v39n5/rme170517.pdf

Diestra Goicochea, N. T. (2017). La contaminación ambiental y su influencia en la salud de la población. Ciencia y Tecnología, 13(03), 93-102. Obtenido de https://revistas.unitru.edu.pe/index.php/PGM/article/view/1881

Estrada Paneque, A., Gallo González, M., \& Nuñez Arroyo, E. (2016). Contaminación ambiental, su influencia en el ser humano, en especial: el sistema reproductor femenino. Universidad y Sociedad, 8(2), 80 - 86. Obtenido de http://scielo.sld.cu/pdf/rus/v8n3/rus10316.pdf

Amable Álvarez, I., Méndez Martínez, J., Delgado Pérez, L., Acebo Figueroa, F., de Armas Mestre, J., \& Rivero Llop, M. (2017). Contaminación ambiental por ruido. Revista Médica Electrónica, 39(3), 640-649. Obtenido de http://scielo.sld.cu/scielo.php?script=sci_arttext\&pid=S1684$18242017000300024 \& \operatorname{lng}=$ es\&tlng=es.

Ballester, F. (2005). Contaminación atmorférica, cambio climático y salud. Rev Esp Salud Pública, 2, 159-175. Obtenido de https://www.scielosp.org/article/ssm/content/raw/?resource_ssm_path=/media/asset s/resp/v79n2/v79n2a05.pdf

Banco Mundial. (8 de Abril de 2018). bancomundial.org. Obtenido de Reducir la contaminación: https://www.bancomundial.org/es/topic/environment/brief/pollution

Barahona, Cesar Alexis Castillo. (2016). contaminantes no degradables. Obtenido de https://sites.google.com/site/cesarcastillo2611 contaminacion/contaminantes-nodegradables

Carrillo, J. (miercoles de septiembre de 2017). Sociedad Peruana de Derecho Ambiental (SPDA). Obtenido de Sociedad Peruana de Derecho Ambiental (SPDA): 


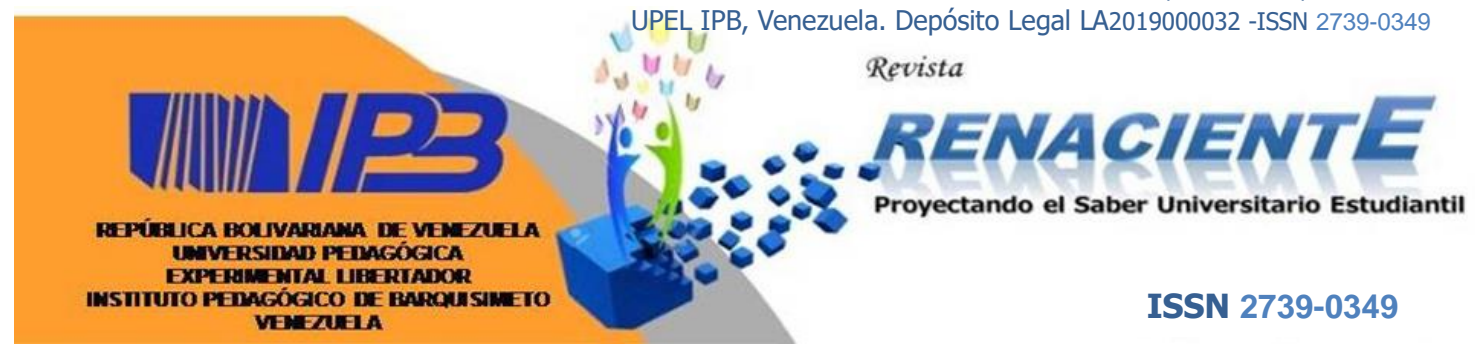

https://www.actualidadambiental.pe/alertan-sobre-contaminacion-e-intoxicacioncronica-en-la-oroya-y-cerro-de-pasco/

Ciencia. (1 de Marzo de 2007). Los efectos de la contaminación ambiental. Ciencia, 58(1). Obtenido de https://www.amc.edu.mx/revistaciencia/index.php/edicionesanteriores/35-vol-58-num-1-enero-marzo-2007/ambiente-y-salud/73-lacontaminacion-ambiental-y-nuestra-salud

Ecologistas en Acción. (2006). Causas de la contaminación del aire. Obtenido de Ecologistas en Acción: https://www.ecologistasenaccion.org/5681/causas-de-lacontaminacion-del-aire/

Gonzales, G. F., Zevallos, A., Gonzales Castañeda, C., Nuñez, D., Gastañaga, C., Cabezas, C., . . . Steenland, K. (2014). Contaminación ambiental, variabilidad climática y cambio climático: una revisión del impacto en la salud de la población peruana. Revista Peruana de Medicina Experimental y Salud Publica, 31(3), 547-556. Obtenido de http://www.scielo.org.pe/scielo.php?pid=S172646342014000300021\&script=sci_arttext\&tlng=en

Lara, A. R. (mayo de 2020). Manual MSD. Obtenido de MD, University of Colorado: https://www.msdmanuals.com/es-pe/hogar/trastornos-del-pulm\%C3\%B3n-y-lasv\%C3\%ADas-respiratorias/enfermedades-pulmonares-de-origenambiental/enfermedades-relacionadas-con-la-contaminaci\%C3\%B3natmosf\%C3\%A9rica

OMS. (2019). Contaminación del Agua. Obtenido de Contaminación del Agua: https://www.iberdrola.com/sostenibilidad/contaminacion-del-agua

Organización de las Naciones Unidas para la Alimentación y la Agricultura. (7 de Mayo de 2018). FAO. Obtenido de La contaminación de los suelos está contaminando nuestro futuro: http://www.fao.org/global-soilpartnership/resources/highlights/detail/es/c/1127957/

Organización Mundial de la Salud. (14 de Junio de 2019). Agua. Obtenido de https://www.who.int/es/news-room/fact-sheets/detail/drinking-water

Osseiran, N., \& Lindmeier, C. (2 de mayo de 2018). Nueve de cada diez personas de todo el mundo respiran aire contaminado. Obtenido de Oganización Mundial de la Salud: https://www.who.int/es/news/item/02-05-2018-9-out-of-10-people-worldwidebreathe-polluted-air-but-more-countries-are-taking-action 


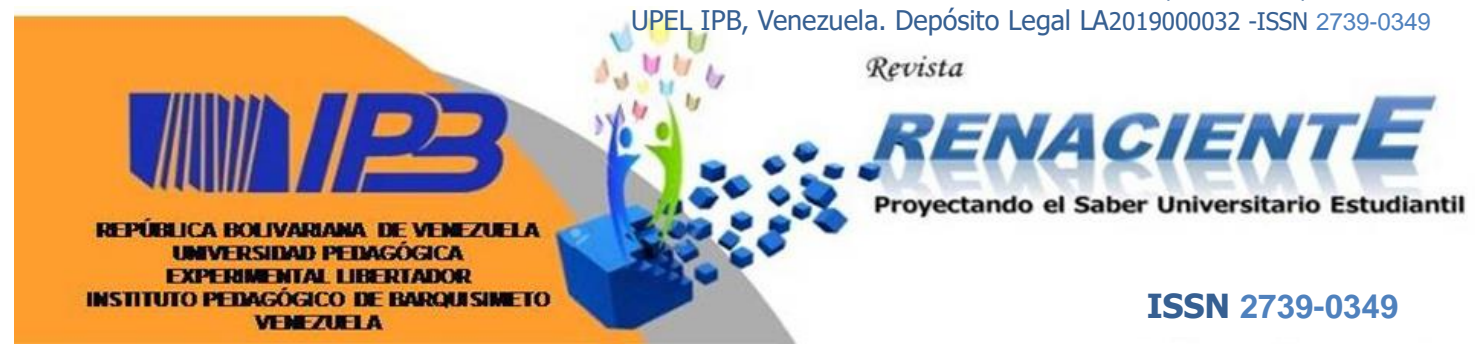

Portillo, S. R. (11 de febrero de 2020). Ecología verde. Obtenido de tipos de contaminacion : https://www.ecologiaverde.com/tipos-de-contaminantes-ambientales-2477.html

SPDA. (27 de Setiembre de 2017). actualidadambiental.pe. Obtenido de https://www.actualidadambiental.pe/alertan-sobre-contaminacion-e-intoxicacioncronica-en-la-oroya-y-cerro-de-pasco/

Vargas Marcos, F. (2005). La Contaminación Ambiental como Factor Determinante de la Salud. Salud Pública, 79(2), 117-127. Obtenido de https://www.scielosp.org/article/ssm/content/raw/?resource_ssm_path=/media/asset s/resp/v79n2/v79n2a01.pdf

Vazquez, E. (21 de Agosto de 2017). agua. Obtenido de EcoSiglos: https://agua.org.mx/contaminacion-del-agua-causas-consecuencias-soluciones/

Voltaire. (2000). Contamiancion del suelo. Obtenido de https://www.tesisenred.net/bitstream/handle/10803/11036/Tasm03de16.pdf

Williams, A. d. (2013). Efectos nocivos de la contaminación ambiental sobre la embarazada. Scielo, 51(2), 226-238. doi:http://scielo.sld.cu/pdf/hie/v51n2/hie11213.pdf 